\title{
Performance Assessment of Stress Concentration Reduction Methods in Mild Steel Transmission Shaft
}

\author{
Ravindra Kannojiya, Akshat Shukla, Mohit Jain, Sarthak Kaintura, Aditya Bachchan
}

\begin{abstract}
A shaft is subjected to tensile stress, compressive stress, torsional force and bending moment due to reaction on the components. The stress distribution in a shaft can be is similar to the flow of fluid in a channel. So, it is perfectly logical to use the fluid analogy to understand the phenomenon of stress concentration. When the cross section is uniform the flow is uniform whereas if there is a sudden change in the cross section then the velocity increases to keep the flow rate constant .The same phenomenon is observed in the shaft i.e. when the cross section of the shaft is uniform throughout, the stresses are uniform where as if the cross section changes abruptly then the stress lines come closer to each other in order to keep the force same. When there are sharp changes then it results in stress concentration.The effect of stress concentration can be reduced effectively as there are numerous discontinuities which makes it impossible to eradicate it fully.This could be done by numerous some of which are removal of material, providing fillet radius and also by choosing appropriate material for manufacturing . Software like Solid works can be used for the design and analysis of the component. An object drawn with Solid works can be analysed interactively and physical information can be extracted from it.
\end{abstract}

Keywords: Stress Distribution, Phenomenon, Analysed Interactively, Physical Information.

\section{INTRODUCTION}

Transmission shaft is a circular cross sectioned rotating member used to transmit power from engine or motor to the differential from which the power is further transmitted to the wheel s. It was invented by Louis Renault in 1898 .It is also called as 'power shaft' in BritishEnglish. It provides the point where useful power is needed from the motor. Generally in automobile industry the shafts delivers the main driving power from the final reduction gear of the power train system to the front wheel in front wheel drive vehicles where as in rear wheel drive they supply power to the rear wheels.[1] Generally, shafts are of two types (i) Hollow shafts and (ii) Solid shafts. Hollow shaft is stiffer, offers more strength than solid shaft and has greater natural frequency however it is more expensive and requires more axial space.[2] Whilst in process of transmitting power the shaft witnesses torsional, tensile and compressive stresses.

\section{Revised Manuscript Received on February 05, 2020.}

* Correspondence Author

Mr. Ravindra Kannojiya, Assistant Professor, department of Mechanical department, Amity university (ASET), Noida, Uttar Pradesh, India.

Akshat Shukla, B.Tech student, department of Mechanical department, Amity university (ASET), Noida, Uttar Pradesh, India.

Mohit Jain, B.Tech student, department of Mechanical department, Amity university (ASET), Noida, Uttar Pradesh, India.

Sarthak Kaintura, B.Tech student, department of Mechanical department, Amity university (ASET), Noida, Uttar Pradesh, India.

Aditya Bachchan, B.Tech student, department of Mechanical department, Amity university (ASET), Noida, Uttar Pradesh, India.

(C) The Authors. Published by Blue Eyes Intelligence Engineering and Sciences Publication (BEIESP). This is an open access article under the CC BY-NC-ND license (http://creativecommons.org/licenses/by-nc-nd/4.0/)
The flow of these stresses can be understood with the flow of water in a pipe or stresses in a circular shaft flows in the same way as water flows in a circular pipe. When the cross section of the pipe is uniform throughout then the flow of the fluid is also uniform where as if there is a sudden change in the cross section the velocity of the fluid increases or decreases to keep the discharge of the flow so as to satisfy the continuity equation in one dimension.Similarly when the cross section of the circular shaft is uniform throughout the flow is also uniform but if there is an abrupt change in the cross section then the rate of flow of stress gets affected and is concentrated at that point . This phenomenon of stress concentration causes failure in the shaft in the form of cracks or fracture[3]. This failure of the transmission shaft can't be fully eradicated but various methods can be used to reduce stress concentration and increase the fatigue life of the drive shaft. This includes selection of proper material for the manufacturing of shaft, machining of fillets and grooves at appropriate location and of appropriate size [4]. Proper material can be selected based on the properties of the material and the proper theory of failure. Various work has been previously done in order to study the effect of these factors on the performance of the transmission shaft.

Myungshinetal [5]studied the effect of stress reliving grooves on axle shaft. Two stress reliving grooves were applied on the snap ring cut vicinity on the long span axle shaft .FEA was used to investigate qualitatively the effect of the stress reliving grooves. They concluded that when both the sides of the snap ring cut have grooves machined and the grooves are moved closer to the snap ring cut when the radius of the relief grooves is larger then it results in reduction of the stress concentration upto $22.3 \%$

Rushton [6]performed a preliminary investigation of the torsional stress concentration for circular shafts containing circular grooves, which was determined with the help of an analogue computer.He concluded that torsion testing of grooved shafts exhibits that values due to Nuber tends to over estimate the stress concentration factor within the limited range of parameters but for deep grooves they are accurate.

Sriram et al[7] studied the relation between the critical speed and frequency of composite shaft and it was concluded that replacement of conventional steel shaft by composite material provided ample weight saving which makes available surplus power and and it also reduces the vibration produced in the transmission shaft compared to the conventional shaft because of the vibration damping ability of composite material.

Jayanaidu et al[8] found that the replacement of conventional drive shaft results in reduced weight ratio of mobile. 


\section{Performance Assessment of Stress Concentration Reduction Methods in Mild Steel Transmission Shaft}

Finite element analysis was used to predict the deformation of shaft and it was concluded that the total deformation of steel ,titanium was to be better than conventional steel.

Zappalorato et al [9] Theoretical results have been compared with numerical data as determined from two model sweakened by a parabolic notch and a hyperbolic notch,both having the local axis inclined to $45 \mathrm{u}$ with respect to the round bar longitudinal axis.The agreement was found to be very satisfactory.

Tipton et al [10] performed detailed FEA over a wide range of filled shafts to define the following relations for tension loading and bending

(i) revised elastic stress concentration factor

(ii) revised elastic von mises equivalent stress concentration factor

(iii) the maximum stress locationin the fillet

It was demonstrated that the first relation reveal the full multiaxialelastic state of stress and strain at the maximum stress location.

Gujar et al [11] studied a shaft employed in an inertia dynamometer rotated at $1000 \mathrm{rpm}$.To calculate the stress induced, torque acting on the shaft is used. To calculate fatigue stress concentration factor, stress concentration factor was calculated. The fatigue life prediction is performed based on FEA and analytical method .It was concluded that the working alternating / mean stress within limit value and increased fatigue strength for infinite life below material endurance strength limit.

Arun et al [12] studied on piece hybrid aluminium E glass epoxy composite drives shaft for automobile applications .Torsional buckling ,torsional strength and bending natural frequency were considered as basic requirements .Hybrid shaft of aluminium and epoxy was made in which aluminium transmits the torque and bending natural frequency is increased by e glass epoxy .Four cases of aluminium tube were studied with different layer of composite material wounded .Their was an enhancement of $66 \%$ in maximum static torsion in multi layered shaft than pure aluminium and $42 \%$ mass reduction was achieved.

Dinesh et al [13] studied the properties of e glass / epoxy , high strength carbon / epoxy and high modulus carbon / epoxy for the replacement of two piece steel drive shaft by a single piece shaft for for automobile application .Torsional buckling ,torque transmission and natural bending frequwncy were considered as basic parameters and it was concluded that $48.36 \%$ o, $86.9 \%$ and $86.9 \%$ weight saving was achieved by e glass / epoxy , high strength carbon / epoxy and high modulus carbon / epoxy shafts respectively. It was also observed that torquw transmission capacity of the shaft reduces due to centrifugal forces.

Dharmadhikari et al [14 ] optimisation of drive shaft via ANSYS and generic algorithm was done .Since composite shaft have high specific stiffness and strength with respect to conventional shaft so it is considered to be a better option for manufacturing .Conventional steel delivers low specific stiffness which results in poor performance of shaft as a product In general a shaft is made into two parts for achieving greater natural bending frequency but it also increases the weight which makes it not suitable for the present scenario and it was concluded that replacement of conventional shaft with a composite one results in reduction in weight ratio .This was predicted by F.E.A . which also predicts that single piece high strength carbon / epoxy

composite drive shaft is a better replacement for two piece conventional steel drive shaft in a vehicle.

Ramyasri et al [15] investigated the variation of stress concentration factor under cyclic loading for different method of reduction .The solution of transient structural problems was made based on theory of stress by three dimensional F.E.A. . The analysis was done in two phases in which the first phase consisted of static analysis of stress concentration with fully reversed bending loads the result of the reduction method like notches, simple fillet and undercut is taken to reduce the stress concentration.

\section{EXPERIMENTAL METHOD}

The test was carried out on the shaft to determine the mechanical properties such as tensile strength and torsion strength of the shaft made of most feasible materials and the comparison of filleted and non-filleted shafts. Following steps were followed for completion of the experiment.

1)Selection of material of which the shaft is to made from

2) Selection of mode of making and finishing of shaft.

3) Selection of criterion on which the shaft is to be judged.

4) Selection of tests to be performed on the shaft for yielding its properties.

5) Determination of the dimensions of the shaft according to the range of testing apparatus available and as per the relations mentioned in the machine design data book.

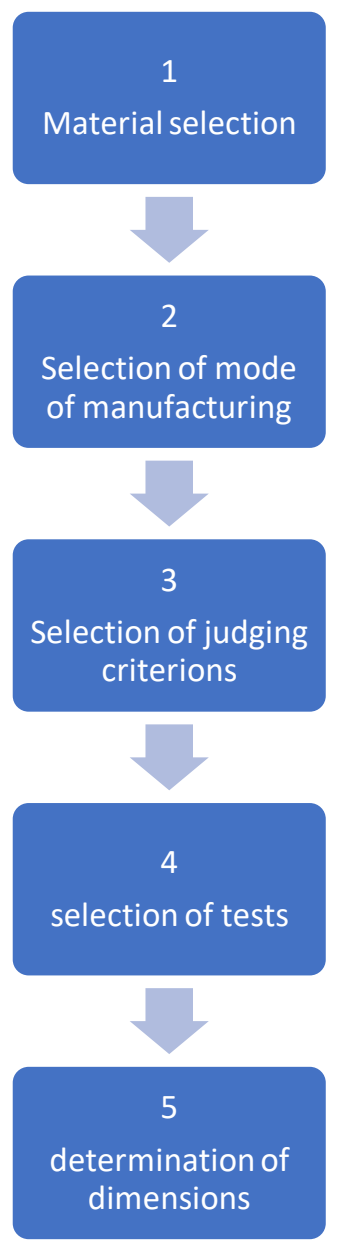

Fig1: flow chart for execution of experiment 
Selection of material

Table1: Table for material selection

\begin{tabular}{|c|c|c|c|c|c|c|c|}
\hline Properties & $\begin{array}{c}\text { Low } \\
\text { carbon } \\
\text { steel } \\
\text { AISI } \\
1018\end{array}$ & $\begin{array}{c}\text { Nickel } \\
\text { Chromium- } \\
\text { Molybdenum } \\
\text { steel } \\
\text { AISI 8620 }\end{array}$ & $\begin{array}{c}\text { Stainless } \\
\text { steel grade } \\
304\end{array}$ & $\begin{array}{c}\text { Stainless } \\
\text { steel } \\
\text { grade304 L }\end{array}$ & Cast iron & $\begin{array}{c}\text { EN } \\
8 / \text { AISI } \\
1040\end{array}$ & $\begin{array}{c}\text { Cold rolled } \\
\text { c1045 steel }\end{array}$ \\
\hline $\begin{array}{c}\text { Tensile } \\
\text { strength(mpa) }\end{array}$ & 440 & 530 & 515 & 485 & $115-620$ & 620 & $570-700$ \\
\hline $\begin{array}{c}\text { yield } \\
\text { strength(mpa) }\end{array}$ & 370 & 385 & 215 & 210 & $65.5-172$ & 415 & 310.2641 \\
\hline $\begin{array}{c}\text { Corrosion } \\
\text { resistant }\end{array}$ & Fair & Fair & Excellent & excellent & excellent & Fair & Not good \\
\hline Density & 7870 & 7850 & 7999 & 8000 & $\begin{array}{c}6800- \\
7800\end{array}$ & 7845 & 7870 \\
\hline
\end{tabular}

In general transmission shafts are manufactured from medium carbon steels with a carbon content of 0.15 to 0.40 percent such as 30C8 or 40C8 also known as machinery steels. When greater strength is needed high carbon steel such as 45 C8 or 50C8 or alloy are employed. Alloy steels include nickel, molybdenum and nickel chromium steel. Alloy steels are costly compared to plain carbon steels. However, they have higher strength hardness and toughness. Alloy steel have higher resistance against corrosion compared with plain carbon steel. Since they are more expensive so this makes them less feasible too.

According to the above table AISI 1018 was selected for the experimental work. AISI 1018 show very good tolerance against applied load and has a very good resistivity against corrosion. The material can be heat treated and have excellent weldability. Both the materials are used in manufacturing of crank shafts and transmission shafts

\section{Preparation of specimen}

Shafts are manufactured by hot rolling and finished to size either by cold drawing turning or grinding. Shafts with high strength are produced by cold drawing. However cold drawing also have disadvantages which are not good for the quality of the shaft and hampers the performance and life of the shaft. The tolerance of their diameter and straight ness are not very close compared to shafts which are finished via turning and grinding process. There is residual stresses near the ends of the shaft if it is finished by cold drawing. These residual stresses are released when the shaft is further machines, hence resulting in distortion in the shaft. The correction of the distorted and twisted shaft is difficult and costly operation. It requires highly labour. This is the reason why the shafts were machined by the process of plain turning on centre lathe machine and grinding. Surface finishing was also done on the centre lathe machine.

Specimens of AISI 1018 and AISI 1040 were made. Three specimens with stress removing fillets were made with appropriate $d / D, r / D$ ratio as per proper stress concentration factor. Three specimens without stress removing fillets were made but $d / D$ ratio was maintained. The specimens were made on a centre lathe machine . Proper dimensions were achieved by process like turning with the help of tungsten carbide cutting tool and parting tool. After completion of turning chamfering was also done so that the specimen can be properly gripped in the UTM machine.

\section{Tensile testing}

The testing of the specimen was done on a universal testing machine.

The specimen was loaded on the UMT machine and the tensile load and the elongation in the shaft was recorded until the shaft experienced fracture.

\section{Torsional testing}

The shaft was mounted on the torsional testing machine with the help of special jigs which prevent the slipping of the shaft from the machine grip. The load as well as the angle of twist of the shaft were recorded time to time until the shaft experienced fracture.

\section{RESULT}

The results obtained from the tensile test, torsion test and static analysis of mild steel shaft without fillet and mild steel with fillet were compared. In tensile testing of mild steel shaft without fillet the tensile stress obtained under the load of maximum $104 \mathrm{KN}$ was $552.83 \mathrm{MPa}$ whereas stress in mild steel shaft with fillet the stress obtained under maximum load of $118 \mathrm{KN}$ was $627.252 \mathrm{MPa}$. In torsion testing of mild steel shaft without fillet the average torsional stress obtained was $54.7 \mathrm{Mpa}$ at 100 degree and with fillet was $94.2 \mathrm{Mpa}$.

The static analysis was also carried out on mild steel shaft in SOLIDWORKS SIMULATION. For tensile test in mild steel shaft without fillet the tensile stress obtained was 747.8 Mpa whereas in the specimen with fillet stress obtained was 792.84 Mpa.

In torsional test the torsional stress obtained in shaft without fillet was $60.4 \mathrm{Mpa}$ whereas in shaft without fillet the torsional stress obtained was 99.080 Mpa.

Table2: stresses obtained by testing the shaft on UTM \& Torsion testing machine

\begin{tabular}{|c|c|c|}
\hline Material & \multicolumn{2}{|c|}{ MILDSTEEL SHAFT } \\
\hline Tensile stress(Mpa) & With fillet & Without fillet \\
\hline $\begin{array}{c}\text { Torsional } \\
\text { stress(Mpa) }\end{array}$ & $\mathbf{6 2 7 . 2 5 2}$ & 552.83 \\
\hline
\end{tabular}




\section{Performance Assessment of Stress Concentration Reduction Methods in Mild Steel Transmission Shaft}

\section{Simulation results}

The simulation results obtained clearly show the effectiveness of the fillet used in the shaft. The figures shown below clearly verify the reduction of stress concentration in the shaft.

\section{1)tensile test}

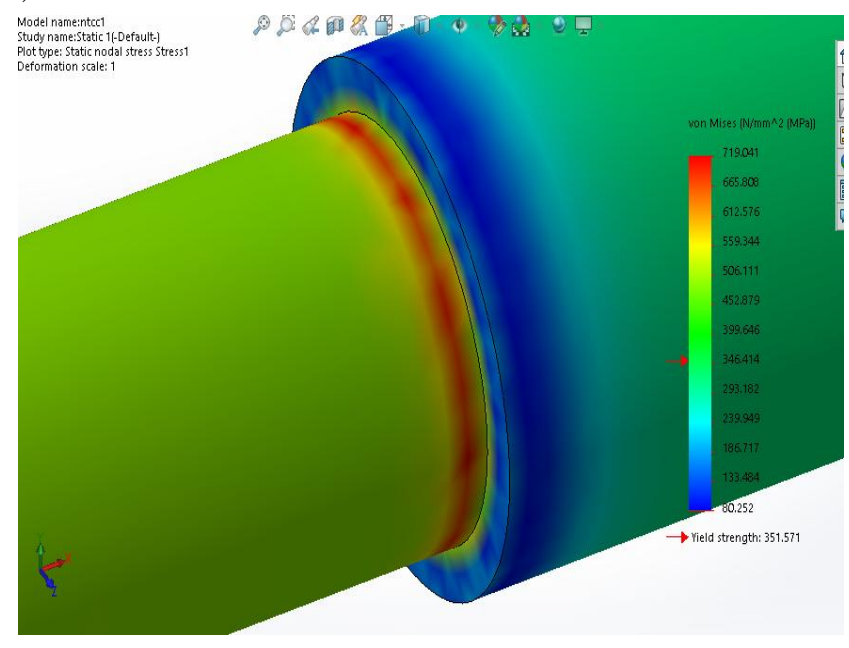

Fig1: Shaft without fillet

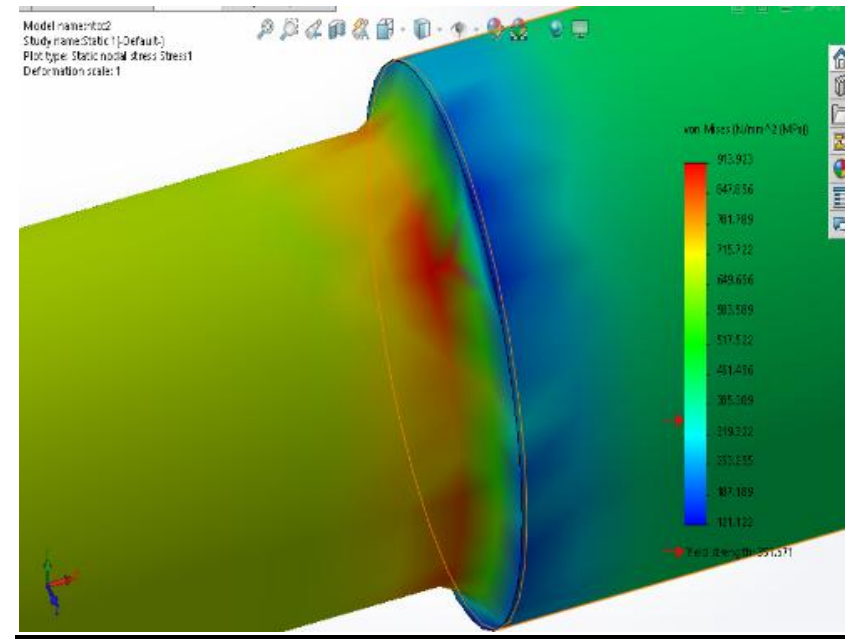

Fig2: Shaft with fillet

2) Torsional test

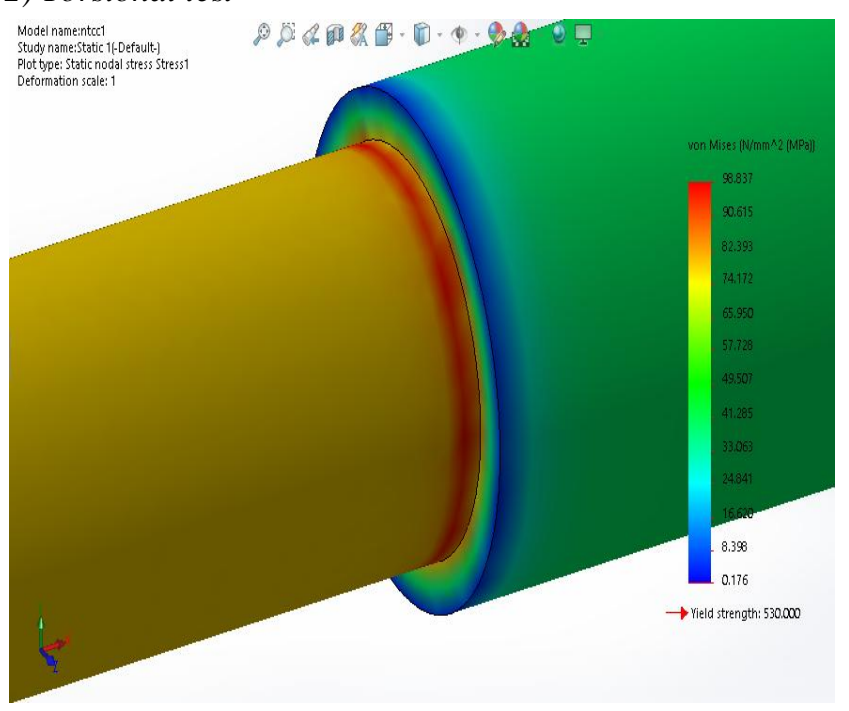

Fig3: Shaft without fillet

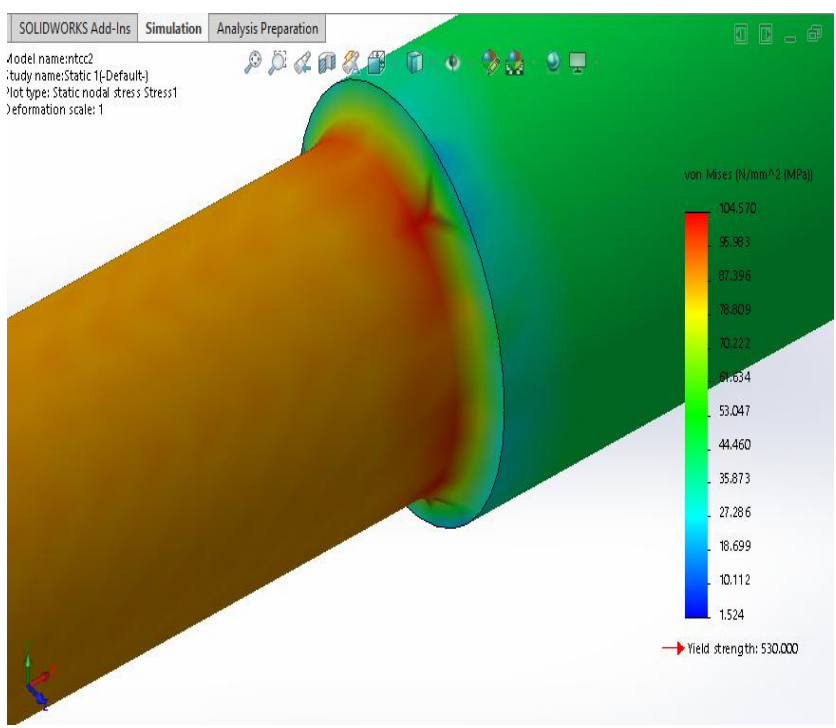

Fig4: Shaft with fillet

\section{CONCLUSION}

From the obtained results it was concluded that the tensile stress tolerated by mild steel shaft without fillet was less than the Stress tolerated by the mild steel shaft with fillet and the same was observed for the torsional test and hence simulation results were verified. This evidently shows the efficiency of fillet as a method of stress reduction. Because of the fillet the force flows without any hurdles and it also decreases the effect at the portion with sudden change in cross section.

\section{REFERENCES}

1. Saxena, Gaurav. "Optimal design and analysis of composite drive shaft for a light commercial vehicle".

2. T .Balusamy, T.S.N. Sankara narayanan ,K. Ravichandran ,Min Ho Lee , T. Nishimura, Surface Nanocrystallization of EN8 Steel: Correlation of Change in Material Characteristics with Corrosion Behavior

3. S.F. Asokanathan , P.A. Meehan, Non-linear linear vibration of a torsional system driven by Hooke's joint

4. M.A. Badie, E. Mahdi $\Uparrow$, A.M.S. Hamouda An investigation into hybrid carbon/glass fiber reinforced epoxy composite automotive drive shaft

5. A. Göksenli *, I.B. Eryürek Failure analysis of an elevator drive shaft

6. Farzad Vesali, Mohammad Ali Rezvani* and Mohammad Kashfi Dynamics of universal joints, its failures and some propositions for practicallyimproving its performance and life expectancy

7. M. Chouksey, J.K. Dutt *, S.V. Modak Modal analysis of rotor-shaft system under the influence of rotor-shaftmaterial damping and fluid film forces

8. G.Kaviprakash , I. Daniel Lawrence, C . Ramesh Kannan , A. Prince Reagan Design and Analysis of Composite Drive Shaftfor Automotive Application

9. Khairul Akmal Shamsuddin, Mohd Syamil Tajuddin,Megat Mohd Amzari Megat Mohd Aris,Mohd Nurhidayat Zahelem , Stress Distribution Analysis of Rear Axle Housing by using Finite Elements Analysis.

10. Ercan Sevkat $\Uparrow$, Hikmet Tumer Residual torsional properties of composite shafts subjected to impactloadings .

11. R. Srinivasa Moorthy, Yonas Mitiku \& K. Sridhar Design of Automobile Driveshaft using Carbon/Epoxy and Kevlar/Epoxy Composites.

12. A V Hari Babu, Dr B Durga Prasad Failure analysis of rear axle differential pinion shaft .

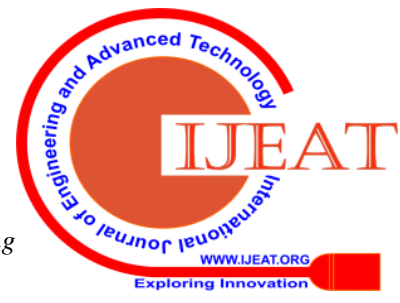




\section{AUTHORS PROFILE}

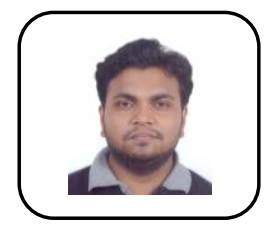

Mr. Ravindra Kannojiya, Assistant Professor at Amity university (ASET) Mechanical department.

FacultyCo-ordinator: ASME Amity student section

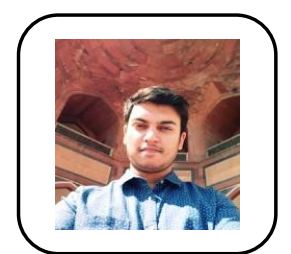

Akshat Shukla, B.Tech (MECHANICAL) student at AMITY University, Noida.Vice President: ASME Amity student section

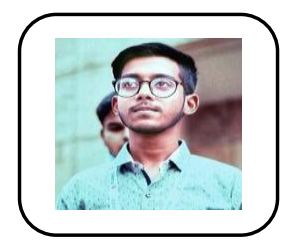

Mohit Jain, B.Tech (MECHANICAL) student at AMITY University, Noida.President: ASME Amity student section

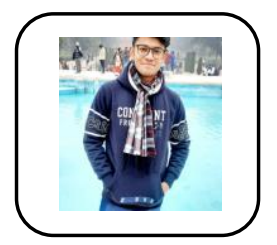

Sarthak Kaintura, B. Tech (MECHANICAL) student at AMITY University, Noida.Treasurer: ASME Amity student section

Aditya Bachchan, B.Tech (MECHANICAL) student at AMITY University, Noida.Secretary: ASME Amity student section 